\title{
Superior strength-ductility CoCrNi medium-entropy alloy wire
}

\author{
Jun-Peng Liu ${ }^{a, b, c}$, Jin-Xi Chen ${ }^{a, b, c}$, Tian-Wei Liu ${ }^{a, b, c}$, Chen Li ${ }^{\mathrm{a}, \mathrm{b}, \mathrm{c}}$, Yan Chen ${ }^{\mathrm{a}, \mathrm{b}, \mathrm{c}, *}$, \\ Lan-Hong Dai ${ }^{\text {a,b,c,* }}$ \\ a State Key Laboratory of Nonlinear Mechanics, Institute of Mechanics, Chinese Academy of Sciences, Beijing 100190, China \\ ${ }^{\mathrm{b}}$ School of Engineering Science, University of Chinese Academy of Sciences, Beijing 101408, China \\ c CAS Center for Excellence in Complex System Mechanics, Beijing 100190, China
}

\section{A R T I C L E I N F O}

\section{Article history:}

Received 17 January 2020

Revised 31 January 2020

Accepted 2 February 2020

Available online 13 February 2020

\section{Keywords:}

Metallic wire

Mechanical properties

Twinning

Phase transformation

\begin{abstract}
A B S T R A C T
High strength-ductility is the prerequisite requirement for the widely used steel wires in engineering applications. Traditional strengthening strategies on these wires are suffocated inevitably by strengthductility trade-off dilemma. Recent emerging medium-entropy alloys (MEAs) usually exhibits excellent ductility but relatively lower strength. In this paper, a novel CoCrNi MEA wire with superior mechanical properties was successfully fabricated by heavily drawing process. The yield strength, ultimate tensile strength and elongation could reach 1.5 GPa, 1.8 GPa and 37.4\% at liquid-nitrogen temperature, respectively. In-depth microstructure characterization indicates this superior strength-ductility derives from the synergy of dislocations, high-density twins and clear FCC-HCP phase transition.
\end{abstract}

(c) 2020 Acta Materialia Inc. Published by Elsevier Ltd. All rights reserved.
High strength metallic wire, such as pearlitic steel wire, is widely used in the critical infrastructure, such as large cablestayed bridge, tire cords, special rescue equipment [1,2]. Extensive studies have focused on the pearlitic steel wire owing to its super high tensile strength [3-19], and the underlying strengthening mechanisms have been revealed [20-22], such as internal boundary strengthening, dislocation strengthening, solid solution hardening and the amorphous transition. Yet, confined by the inherent trade-off dilemma, the super high strength usually leads to a dramatically reduced ductility. The elongation of some high strength pearlitic wires is even less than 3\% [23]. To ensure the safety service, the high yield strength (YS), large elongation and strong work-hardening capacity are indispensable in the advanced metallic wires.

High-entropy alloys have attracted wide interests due to their unique properties [24-34]. The novel design concept of multiple principal elements and high configuration entropy makes it a strong candidate to overcome the strength-ductility trade-off [35-43]. Several pioneering advances have made in the HEA wires, and the strength was remarkably enhanced by the drawing process $[44,45]$. Nevertheless, with the increasing strength, work-softening phenomenon and ductility decrement inevitably occur in certain

\footnotetext{
* Corresponding authors.

E-mail addresses: chenyan@Inm.imech.ac.cn (Y. Chen), lhdai@lnm.imech.ac.cn (L.-H. Dai).
}

FCC HEAs. It is a challenge to further enhance the work-hardening capacity and ductility of the high strength HEA wire.

Single-phase FCC CoCrNi medium-entropy alloy exhibits an intriguing combination of strength and ductility, which has a great potential in surmounting the trade-off [39,46-47]. In this work, we successfully prepared an advanced CoCrNi MEA wire with the diameter of $2 \mathrm{~mm}$ by the drawing process. The microstructure of this wire was detailedly characterized. The uniaxial tensile tests demonstrate CoCrNi MEA wire possesses excellent combination of strength and ductility. What is more commendable is that it has good work-hardening capacity at the same time, and even better at low temperature. The structure evolution is also examined to understand the nature of the superior mechanical properties.

With the composition of ternary of CoCrNi alloy (1:1:1 at.\%, purity $>99.9$ wt.\%), a $3 \mathrm{~kg}$ ingot was fabricated by the Vacuum Magnetic Levitation melting device. The ingot was melted three times to ensure the chemical homogeneity, and cooled naturally to room temperature. Then the as-cast round ingot with the diameter of $90 \mathrm{~mm}$ was homogenized by annealing at $1473 \mathrm{~K}$ for $24 \mathrm{~h}$, and hot-forged and rotary swaged at $1423 \mathrm{~K}$ for more than 8 times to ensure the chemical homogeneity and eliminate the casting flaws, and then cooled to room temperature (RT) in air. The final dimension is $15 \mathrm{~mm}$ in diameter. After that, this round rod was hot rolled at $1123 \mathrm{~K}$ to $8 \mathrm{~mm}$ in diameter by the caliber rolling equipment, then the $8 \mathrm{~mm}$ rod was hot-drawn ten times at $1073 \mathrm{~K}$. The drawing speed is $4 \mathrm{~m} / \mathrm{min}$, and the initial holding 

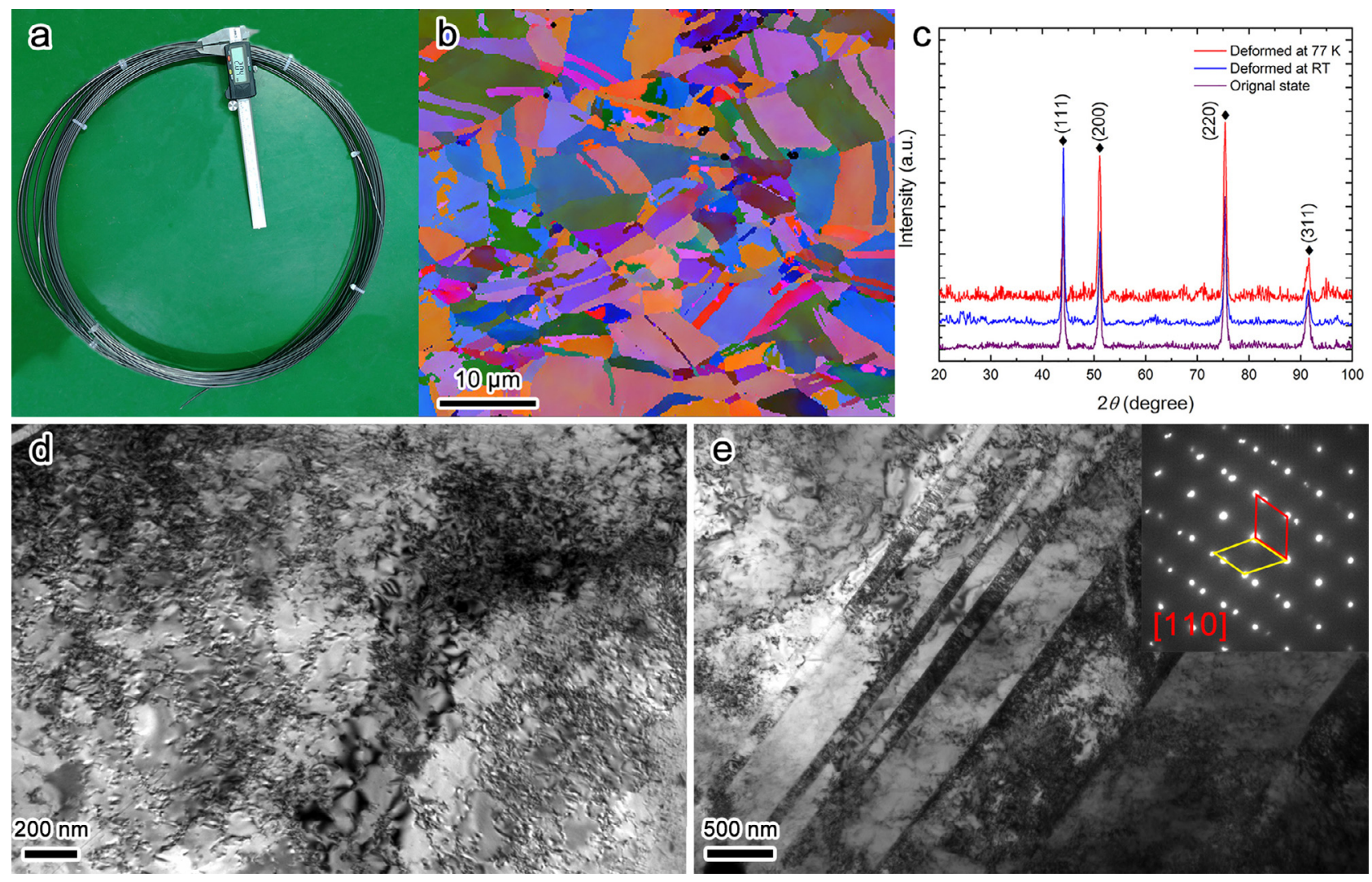

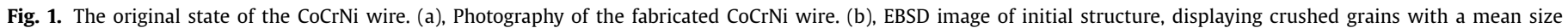

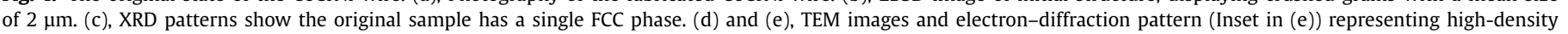
dislocations and few twins in the original sample.

time of the heat-treatment is $3 \mathrm{~min}$. The final dimension of the wire is $2 \mathrm{~mm}$ (See Fig. 1a). Specimens with a gauge length of $20 \mathrm{~mm}$ were tested by a MTS-SANS CMT5000 universal testing machine at a strain rate of $10^{-3} \mathrm{~s}^{-1}$. Tensile tests were performed at RT and liquid-nitrogen temperature $(77 \mathrm{~K})$. For each temperature, at least five samples were tested. X-ray diffraction with $\mathrm{Cu}$ $\mathrm{K} \alpha$ radiation (Rigaku DMAX-RB), scanning-electrical microscopy with electron backscatter diffraction (SEM, Zeiss Supra55), and Transmission electron microscopy (TEM, JEOL JEM-2100) were carried out to indicate the structure evolution of the samples before and after tensile tests. A thin sheet with a thickness of $100 \mu \mathrm{m}$ was ground from the wire using the fine SiC paper. Discs with diameter of $3 \mathrm{~mm}$ were punched out of the foil, then mechanically ground to a thickness of about $45 \mu \mathrm{m}$ and carefully glued in the $3 \mathrm{~mm}$-molybdenum-rings (with inner diameter of $1.5 \mathrm{~mm}$ ). After $24 \mathrm{~h}$, the discs were two-jet polished at $20 \mathrm{~V}$ and $-25{ }^{\circ} \mathrm{C}$, using a mixed solution of $\mathrm{HClO}_{4}: \mathrm{C}_{2} \mathrm{H}_{5} \mathrm{OH}=1: 9$ (Volume fraction) for the TEM tests. All TEM samples of the deformed specimens were extracted from the uniform section.

The as-prepared $\mathrm{CoCrNi}$ wire is a single face-centered cubic (FCC) solid solution, as illustrated by XRD pattern shown in Fig. 1c. The EBSD image in Fig. $1 \mathrm{~b}$ indicates that the sample has irregular grains with a mean size of $2 \mu \mathrm{m}$ and a few twins appear in the initial structure. The bright-field TEM images and the selectedarea electrical diffraction (SAED) patterns in Fig. 1d and 1e verify amount of dislocations and a few $\{111\}$ twins exist in the original specimen.

The measured uniaxial tension engineering stress-strain curves of the $\mathrm{CoCrNi}$ wire at room temperature and $77 \mathrm{~K}$ are shown in Fig. 2a. The YS and ultimate tensile strength (UTS) are 1,100 MPa and $1,220 \mathrm{MPa}$ at room temperature, respectively. It is found from Fig. 2b that this high-strength wire displays an obvious work-hardening behavior, and the uniform elongation exceeds $17 \%$ at RT. When decreasing temperature to $77 \mathrm{~K}$, the YS, UTS and fracture strain reach $1.5 \mathrm{GPa}, 1.78 \mathrm{GPa}$ and $37.5 \%$, respectively. The tensile results indicate this $\mathrm{CoCrNi}$ wire has an excellent combination of strength and ductility. Furthermore, it is noted that all the samples show a pronounced work-hardening behavior after yielding, especially at cryogenic temperature.

Figs. 2c-f show a typical structure feature of the uniform deformation stage in sample after tensile test at RT. The grains are severely stretched, and the high-density lamellar structure appears, where both EBSD and TEM image witness $\{111\}$ twins. In Fig. 2e, plenty of submicron rhomboid blocks appear in the samples, the SAED patterns (as shown in Fig. 2f) confirm that the lamellae in one direction are high-density $\{111\}$ twins, as marked in Fig. 2e. The other direction lamellae are possibly the primary twins [48], or geometrically necessary boundaries (GNBs) [49,50], such as dense dislocation walls (DDWs) or microbands (MBs), and it could be cut off by the twins lamellae, as the red arrow shown in Fig. 2e. This cell-block structure derived from the interaction between the GNBs and high-density nano-twins lamellae implies the localized high-stress in this region, which could strongly refine the grain and block the dislocation motion. The existence of numerous blocked zones could enhance the work-hardening capacity of this high-strength wire.

When decreasing temperature to $77 \mathrm{~K}$, higher-density block structure appears in the deformed $\mathrm{CoCrNi}$ wire, as shown in Fig. 3a. TEM results in Fig. $3 \mathrm{~b}$ and 3e confirm the fine lamella is high-density nano-twins. The inserted SAED patterns (in Fig. 3b and 3e) and dark-field TEM images (displayed in Fig. 3c and 3f) present that the very high density lamella is $\{111\}$ nano-twins. As 

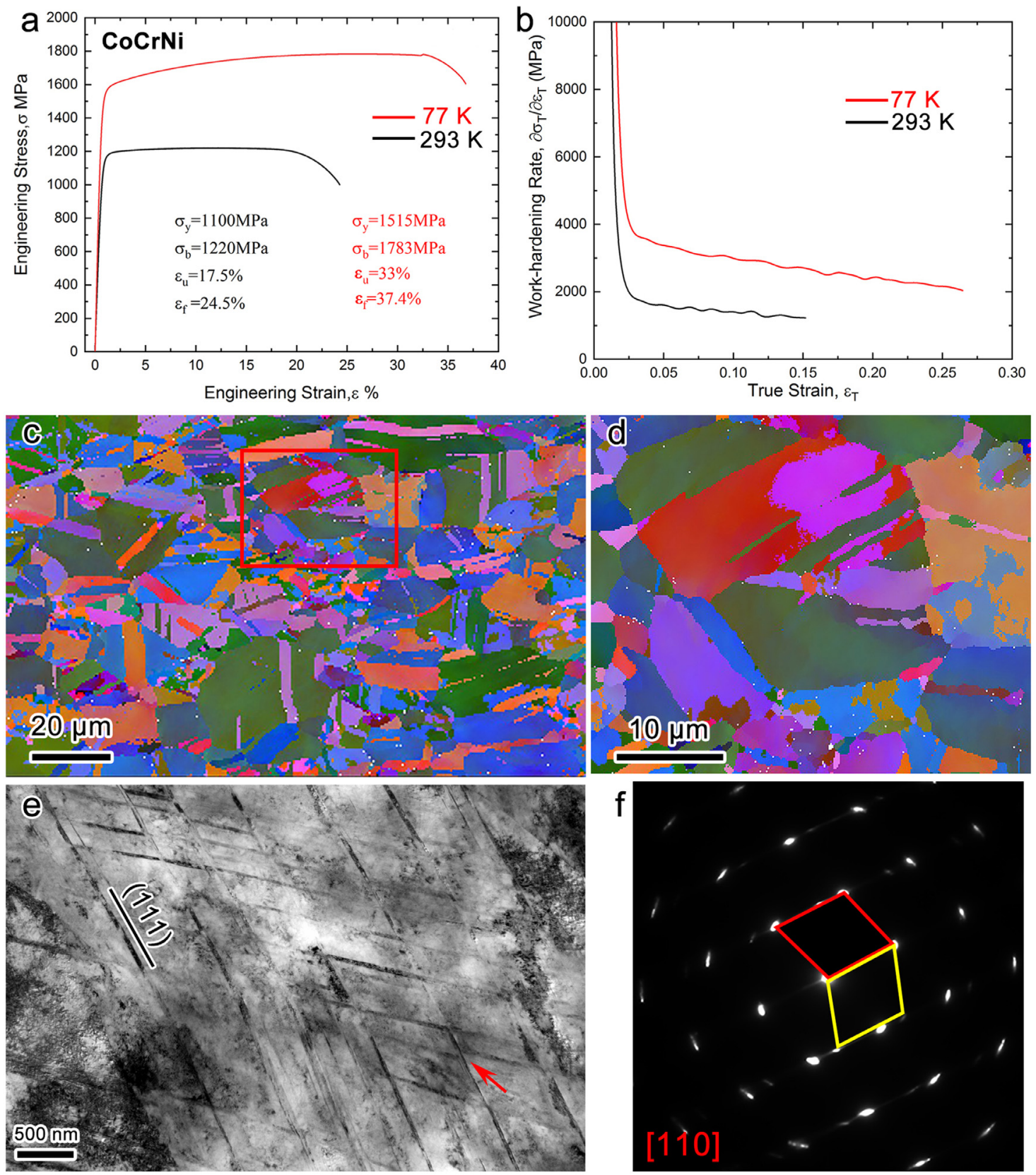

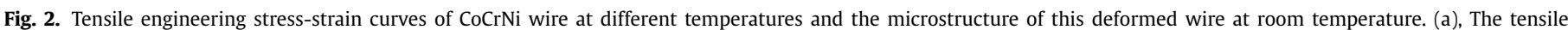

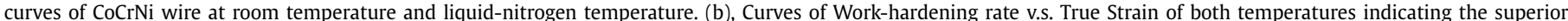

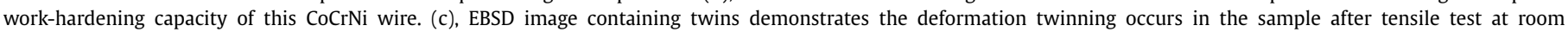

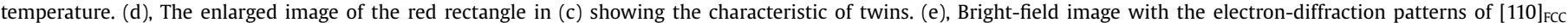
(as shown in (f)) showing the FCC twinning in the sample. The red arrow displays the other direction band could be cut off by the $\{111\}$ twins.

is known, the low stacking fault energy (SFE) promotes deformation twinning (DT) generation. The very low SFE of CoCrNi alloy (approximate $18 \mathrm{~mJ} / \mathrm{m}^{-2}$ [51]) facilitates the abundant nano-twins generation. In addition, high-density stacking faults (SFs) also could be detected in the samples, see Figs. $3 \mathrm{~d}$ and $3 \mathrm{~g}$. These SFs directly result in the very fine lamellae structure. Moreover, although the typical high stress cell-block could confine dislocations in favor of maintaining the high-strength, the high-density nano-twins could be cut off (as shown in Fig. $3 \mathrm{~h}$ and $3 \mathrm{i}$ ) by the other direction deformation MBs which is possibly induced by the dislocation motion. Just like the nanotwinned copper [52-54], the strong interaction between DT and dislocations motion severely subdivides the grains and generates the numerous internal boundaries, which is beneficial to the ductility and work-hardening ability of the high-strength CoCrNi wire.

Apart from the above defects, extremely high-density nanotwins (see the bright-field TEM image in Fig. 4a and dark-field image in Fig. 4b) also appear in the samples deformed at $77 \mathrm{~K}$. More importantly, the FCC $\rightarrow$ HCP phase transition occurs in the CoCrNi wire after deformed at $77 \mathrm{~K}$, as shown in Figs. 4c-f. The typical bright-field TEM images (in Fig. 4c, d) and SAED patterns of $[110]_{F C C} \|[11 \overline{2} 0]_{H C P}$ (inset in Fig. 4c, d) verify the twinning and HCP phase. Figs. $4 \mathrm{e}$ and $4 \mathrm{f}$ display the dark-field images of the twinning and HCP phase in Fig. 4d, respectively. It is clear that 

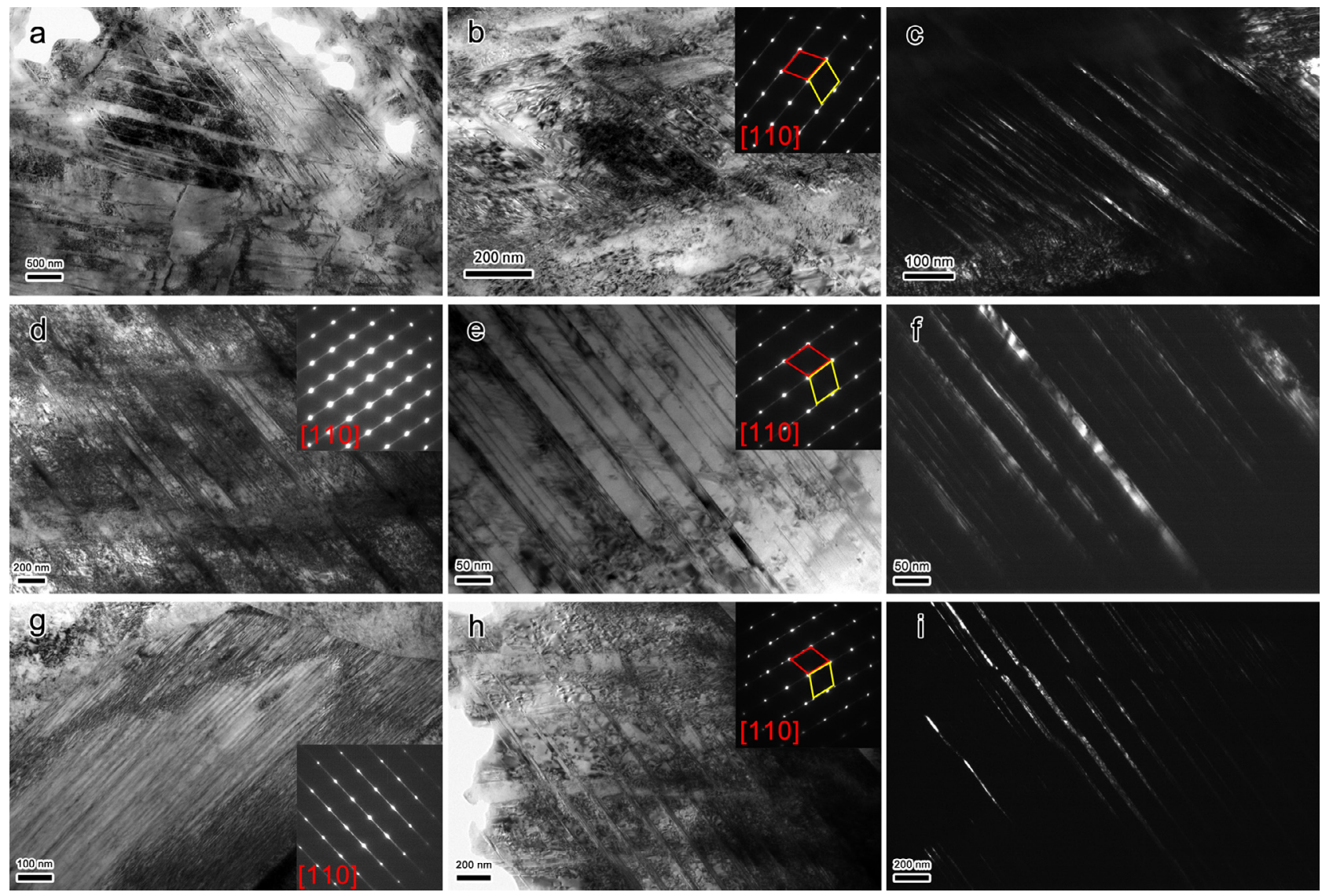

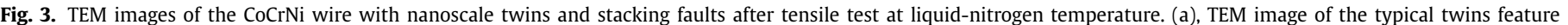

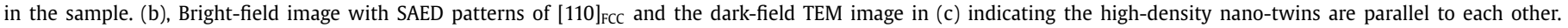

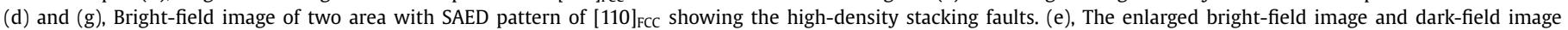

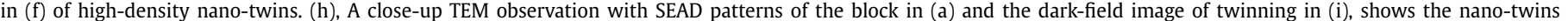
could be cut up by the other direction microband.
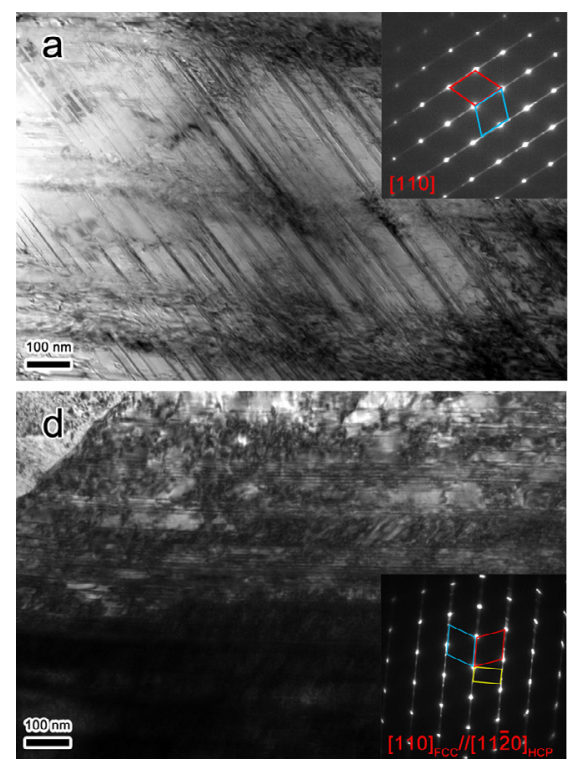
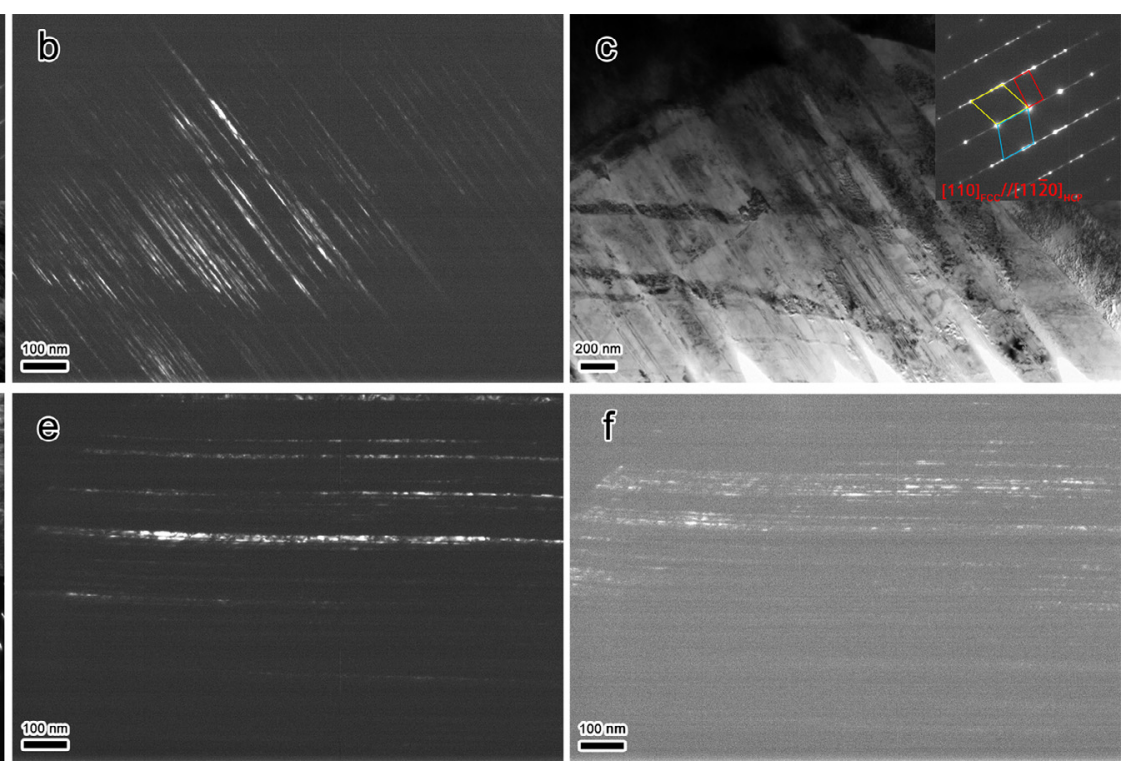

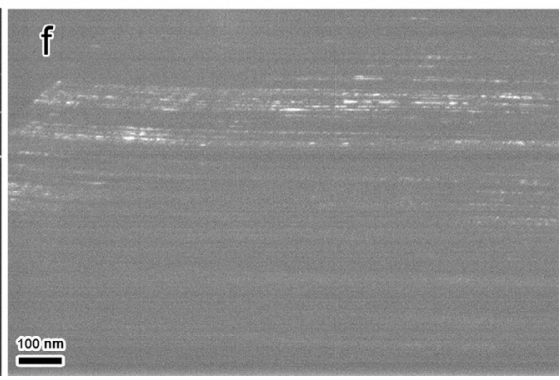

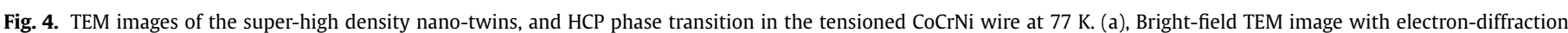

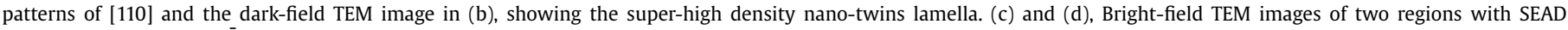

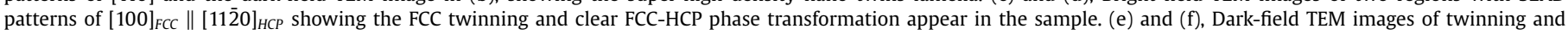
HCP phase in (d), respectively, demonstrate the twins lamella and HCP phase are distributed in hierarchical structure. 
nano-twins and HCP phases are distributed in the hierarchical structure and many nanotwins-HCP boundaries are generated. FCC $\rightarrow$ HCP transition has been found in many HEAs [41,47,55-57] and is favorable to the work-hardening ability enhancement, while not been detected in the high yield strength samples in previous studies. Different with the $\mathrm{Al}_{0.3} \mathrm{CoCrFeNi}$ wire strengthening by B2 particles [44], further studies are still needed as the lack of precipitation strengthening mechanism in the original single-phase CoCrNi wires. The synergy of high-density SFs and nano-twins, together with the fine nanotwins-HCP lamella at cryogenic temperature further generates massive defects and significantly improves the work-hardening capacity. The combined action of the preexisting defects (plenty of dislocations) and subsequent huge quantities of defects (high-density stacking faults, nano-twins, and HCP phases) results in the superior mechanical properties of this CoCrNi wire.

Deformation twinning and the FCC $\rightarrow$ HCP transition in this CoCrNi wire can strongly refine the grains and produce more interface defects, which play a vital role in surmounting the strength-ductility trade-off. The joint action of dislocation motion, DT and phase transformation is in favor of the work-hardening capacity and can lead to the good combination of strength and ductility. Despite decreasing temperature hinders the dislocation motion, the superior mechanical properties are obtained in this $\mathrm{CoCrNi}$ wire depending on the activation of more nano-twins and phase transformation.

In this paper, the advanced CoCrNi wire is fabricated with superior strength-ductility at both room and cryogenic temperature. The exceptional properties at liquid-nitrogen temperature is attributed to the synergy of massive dislocations, high-density SFs, abundant nano-twins and clear FCC-HCP phase transition. The generation of these effectively high-density defects, such as linear defects (dislocations), interface defects (geometrically necessary boundaries, twins boundaries, nanotwins-HCP lamellae boundaries), and volume defects (HCP phases), contributes to the high strength and excellent ductility, and conducts to the superior work-hardening capacity. Hence, compared with the conventional pearlitic steel wire, this advanced MEA wire which can be easily prepared and amplified in factory has a strong potential in engineering application, especially at cryogenic environment. The multiple-mechanisms strategy might guide the design of a new generation of advanced metallic materials applied in the supernormal environments.

\section{Declaration of Competing Interest}

None.

\section{Acknowledgment}

This work is financially supported by the National Key Research and Development Program of China (No. 2017YFB0702003), the NSFC (Nos. 11790292, 11972346 and 51901235), the Strategic Priority Research Program (Nos. XDB22040302 and XDB22040303), the Key Research Program of Frontier Sciences (Grant no. QYZDJSSWJSC011), and the Science Challenge Project (No. TZ2016001). This paper is also supported by the opening project of State Key Laboratory of Explosion Science and Technology (Beijing Institute of Technology). The opening project number is KFJJ18-14M.

\section{Supplementary material}

Supplementary material associated with this article can be found, in the online version, at doi:10.1016/j.scriptamat.2020.02. 002.

\section{References}

[1] M. Zelin, Acta Mater. 50 (2002) 4431-4447.

[2] C. Borchers, R. Kirchheim, Prog. Mater. Sci. 82 (2016) 405-444.

[3] J.D. Embury, R.M. Fisher, Acta Metall. 14 (1966) 147-159.

[4] K. Nakase, I.M. Bernstein, Metall. Trans. A 19 (1988) 2819-2829.

[5] M.H. Hong, W.T. Reynolds, T. Tarui, K. Hono, Metall. Mater. Trans. A 30A (1999) 717-727.

[6] K. Hono, M. Ohnuma, M. Murayama, S. Nishida, A. Yoshie, T. Takahashi, Scr. Mater. 44 (2001) 977-983.

[7] J. Takahashi, T. Tarui, K. Kawakami, Ultramicroscopy 109 (2009) 193-199.

[8] Y.S. Yang, J.G. Bae, C.G. Park, Mater. Sci. Eng. A 508 (2009) 148-155.

[9] C. Borchers, Y. Chen, M. Deutges, S. Goto, R. Kirchheim, Phil. Mag. Lett. 90 (2010) 581-588.

[10] Y.J. Li, P. Choi, C. Borchers, S. Westerkamp, S. Goto, D. Raabe, R. Kirchheim, Acta Mater. 59 (2011) 3965-3977.

[11] J. Takahashi, M. Kosaka, K. Kawakami, T. Tarui, Acta Mater. 60 (2012) 387-395.

[12] Y.J. Li, P. Choi, S. Goto, C. Borchers, D. Raabe, R. Kirchheim, Acta Mater. 60 (2012) 4005-4016.

[13] X.D. Zhang, A. Godfrey, N. Hansen, X.X. Huang, Acta Mater. 61 (2013) 4898-4909.

[14] C. Borchers, A. Lehmberg, M. Deutges, J. Cižek, R. Kirchheim, Scr. Mater. 86 (2014) 17-19.

[15] G. Miyamoto, Y. Karube, T. Furuhara, Acta Mater. 103 (2016) 370-381.

[16] L. Xiang, L.W. Liang, Y.J. Wang, Y. Chen, H.Y. Wang, L.H. Dai, Mater. Sci. Eng. A 757 (2019) 1-13.

[17] L.W. Liang, L. Xiang, Y.J. Wang, Y. Chen, H.Y. Wang, L.H. Dai, Metall. Mater. Trans. A 50 (2019) 4561-4568.

[18] D.S. Wei, L. Li, X.G. Min, F. Fang, Z.H. Xie, J.Q. Jiang, Mater. Character. 153 (2019) $108-114$.

[19] L.W. Liang, Y.J. Wang, Y. Chen, H.Y. Wang, L.H. Dai, Acta Mater. 186 (2020) $267-277$.

[20] C. Borchers, T. Al-Kassab, S. Goto, R. Kirchheim, Mater. Sci. Eng. A 502 (2009) $131-138$.

[21] X.D. Zhang, A. Godfrey, X.X. Huang, N. Hansen, Q. Liu, Acta Mater. 59 (2011) $3422-3430$.

[22] Y.J. Li, D. Raabe, M. Herbig, P. Choi, S. Goto, A. Kostka, H. Yarita, C. Borchers, R. Kirchheim, Phys. Rev. Lett. 113 (2014) 106104.

[23] X.D. Zhang, N. Hansen, A. Godfrey, X.X. Huang, Acta Mater. 114 (2016) 176-183.

[24] B. Cantor, I.T.H. Chang, P. Knight, A.J.B. Vincent, Mater. Sci. Eng. A 375-377 (2004) 213-218.

[25] J.W. Yeh, S.K. Chen, S.J. Lin, J.Y. Gan, T.S. Chin, T.T. Shun, C.H. Tsau, S.Y. Chang, Adv. Eng. Mater. 6 (2004) 299-303.

[26] Y. Zhang, T.T. Zuo, Z. Tang, M.C. Gao, K.A. Dahmen, P.K. Liaw, Z.P. Lu, Prog. Mater. Sci. 61 (2014) 1-93.

[27] D.B. Miracle, O.N. Senkov, Acta Mater. 122 (2017) 448-511

[28] J.C. Rao, H.Y. Diao, V. Ocelík, D. Vainchtein, C. Zhang, C. Kuo, Z. Tang, W. Guo, J.D. Poplawsky, Y. Zhou, P.K. Liaw, J.T.M. De Hosson, Acta Mater. 131 (2017) 206-220.

[29] Z.J. Zhang, H.W. Sheng, Z.J. Wang, B. Gludovatz, Z. Zhang, E.P. George, Q. Yu, S.X. Mao, R.O. Ritchie, Nat. Commun. 8 (2017) 14390.

[30] Z.F. Lei, X.J. Liu, Y. Wu, H. Wang, S.H. Jiang, S.D. Wang, X.D. Hui, Y.D. Wu, B. Gault, P. Kontis, D. Raabe, L. Gu, Q.H. Zhang, H.W. Chen, H.T. Wang, J.B. Liu, K. An, Q.S. Zeng, T.G. Nieh, Z.P. Lu, Nature 563 (2018) 546-550.

[31] E.P. George, D. Raabe, R.O. Ritchie, Nat. Rev. Mater. 4 (2019) 515-534.

[32] Z.Z. Li, S.T. Zhao, R.O. Ritchie, M.A. Meyers, Prog. Mater. Sci. 102 (2019) 296-345.

[33] Q. Li, H. Sheng, E. Ma, Nat. Commun. 10 (2019) 3563.

[34] I. Basu, V. Ocelík, J.T. De Hosson, Acta Mater. 157 (2018) 83-95.

[35] Y.J. Zhou, Y. Zhang, Y.L. Wang, G.L. Chen, Appl. Phys. Lett. 90 (2007) 181904.

[36] O.N. Senkov, G.B. Wilks, J.M. Scott, D.B. Miracle, Intermetallics 19 (2011) 698-706.

[37] M.A. Hemphill, T. Yuan, G.Y. Wang, J.W. Yeh, C.W. Tsai, A. Chuang, P.K. Liaw, Acta Mater. 60 (2012) 5723-5734.

[38] Y. Zhang, T.T. Zuo, Y.Q. Cheng, P.K. Liaw, Sci. Rep. 3 (2013) 1455.

[39] B. Gludovatz, A. Hohenwarter, D. Catoor, E.H. Chang, E.P. George, R.O. Ritchie, Science 345 (2014) 1153-1158.

[40] Y. Zou, H. Ma, R. Spolenak, Nat. Commun. 6 (2015) 7748.

[41] Z.M. Li, K.G. Pradeep, Y. Deng, D. Raabe, C.C. Tasan, Nature 534 (2016) 227-230.

[42] T. Yang, Y.L. Zhao, Y. Tong, Z.B. Jiao, J. Wei, J.X. Cai, X.D. Han, D. Chen, A. Hu, J.J. Kai, K. Lu, Y. Liu, C.T. Liu, Science 362 (2018) 933-937.

[43] J.P. Liu, X.X. Guo, Q.Y. Lin, Z.B. He, X.H. An, L.F. Li, P.K. Liaw, X.Z. Liao, Y.P. Yu, J.P. Lin, L. Xie, J.L. Ren, Y. Zhang, Sci. China Mater. 62 (2019) 853-863.

[44] D.Y. Li, C.X. Li, T. Feng, Y.D. Zhang, G. Sha, J.J. Lewandowski, P.K. Liaw, Y. Zhang, Acta Mater. 123 (2017) 285-294.

[45] W.Y. Huo, F. Fang, H. Zhou, Z.H. Xie, J.K. Shang, J.Q. Jiang, Scr. Mater. 141 (2017) $125-128$.

[46] B. Gludovatz, A. Hohenwarter, K.V.S. Thurston, H. Bei, Z. Wu, E.P. George, R.O. Ritchie, Nat. Commun. 7 (2016) 10602.

[47] J. Miao, C.E. Slone, T.M. Smith, C. Niu, H. Bei, M. Ghazisaeidi, G.M. Pharr, M.J. Mills, Acta Mater. 132 (2017) 35-48.

[48] N.R. Tao, K. Lu, Scr. Mater. 60 (2009) 1039-1043.

[49] D. Kuhlmann-Wilsdorf, N. Hansen, Scr. Mater. 25 (1991) 1557-1562.

[50] Q. Liu, N. Hansen, Scr. Mater. 32 (1995) 1289-1295.

[51] S.F. Liu, Y. Wu, H.T. Wang, J.Y. He, J.B. Liu, C.X. Chen, X.J. Liu, H. Wang, Z.P. Lu, Intermetallics 93 (2018) 269-273. 
[52] K. Lu, L. Lu, S. Suresh, Science 324 (2009) 349-352.

[53] Q.S. Pan, H.F. Zhou, Q.H. Lu, H.J. Gao, L. Lu, Nature 551 (2017) 214-217.

[54] E.W. Qin, L. Lu, N.R. Tao, J. Tan, K. Lu, Acta Mater. 57 (2009) 6215-6225.

[55] F. Zhang, Y. Wu, H.B. Lou, Z.D. Zeng, V.B. Prakapenka, E. Greenberg, Y. Ren, J.Y. Yan, J.S. Okasinski, X.J. Liu, Y. Liu, Q.S. Zeng, Z.P. Lu, Nat. Commun. 8 (2017) 15687.
[56] C.L. Tracy, S. Park, D.R. Rittman, S.J. Zinkle, H. Bei, M. Lang, R.C. Ewing, W.L. Mao, Nat. Commun. 8 (2017) 15634.

[57] Q.Y. Lin, J.P. Liu, X.H. An, H. Wang, Y. Zhang, X.Z. Liao, Mater. Res. Lett. 6 (2018) 236-243. 